\title{
Low-energy shock wave preconditioning reduces renal ischemic reperfusion injury caused by renal artery occlusion ${ }^{1}$
}

\author{
Yuquan Xue', Zhibin Xu", Haiwen Chen', Weimin Gan", Tie Chong'
}

'PhD, Department of Urology, the Second Affiliated Hospital, Xi'an Jiaotong University, Shaanxi Province, China. Conception and design of the study, intellectual content of the study, analysis and interpretation of data, drafting of the manuscript, critical revision, supervised all phases of the study.

"MD, Department of Urology, the Second Affiliated Hospital, Xi'an Jiaotong University, Shaanxi Province, China. Acquisition, analysis and interpretation of data; statistical analysis.

\begin{abstract}
Purpose: To evaluate whether low energy shock wave preconditioning could reduce renal ischemic reperfusion injury caused by renal artery occlusion.

Methods: The right kidneys of 64 male Sprague Dawley rats were removed to establish an isolated kidney model. The rats were then divided into four treatment groups: Group 1 was the sham treatment group; Group 2, received only low-energy (12 kv, $1 \mathrm{~Hz}, 200$ times) shock wave preconditioning; Group 3 received the same low-energy shock wave preconditioning as Group 2, and then the left renal artery was occluded for 45 minutes; and Group 4 had the left renal artery occluded for 45 minutes. At 24 hours and one-week time points after reperfusion, serum inducible nitric oxide synthase (iNOS), neutrophil gelatinase-associated lipocalin (NGAL), kidney injury molecule-1 (KIM-1), creatinine $(\mathrm{Cr})$, and cystatin $\mathrm{C}$ (Cys $\mathrm{C}$ ) levels were measured, malondialdehyde (MDA) in kidney tissue was detected, and changes in nephric morphology were evaluated by light and electron microscopy.

Results: Twenty-four hours after reperfusion, serum iNOS, NGAL, Cr, Cys C, and MDA levels in Group 3 were significantly lower than those in Group 4; light and electron microscopy showed that the renal tissue injury in Group 3 was significantly lighter than that in Group 4. One week after reperfusion, serum NGAL, KIM-1, and Cys Clevels in Group 3 were significantly lower than those in Group 4.
\end{abstract}

Conclusion: Low-energy shock wave preconditioning can reduce renal ischemic reperfusion injury caused by renal artery occlusion in an isolated kidney rat model.

Key words: Ischemic Preconditioning. Lithotripsy, Laser. Nephrons. Ischemia. Reperfusion. Rats. 


\section{Introduction}

The proportion of nephron-sparing surgeries (NSSs) has sharply increased in recent years ${ }^{1-3}$. NSS requires blocking of the renal artery, and removal of large renal tumors, multiple tumors, and tumors near the collection system may require occlusion for more than 30 minutes ${ }^{4}$, resulting in serious renal ischemicreperfusion (IR) injury. Reducing renal IR injury in NSS remains a challenge. Renal IR injury in NSS can be reduced by short ischemia time and by regional or zero ischemia techniques, but these methods require great skill to perform, making widespread implementation difficult ${ }^{5-7}$. Thus, there is a need for a simple technique that easier to be promoted.

A great deal of effort has been focused on developing new approaches to reduce renal IR injury caused by renal artery occlusion. Ischemic preconditioning (IPC) is a potent protective strategy in which a brief occlusion of ischemia and reperfusion results in tolerance to subsequent ischemia-reperfusion injury ${ }^{8,9}$. It has been demonstrated in multiple tissues and organs including the heart, liver, small intestine, and renal tissues ${ }^{10-13}$.

Low-energy shock waves have been used in many fields to reduce the damage induced by tissue ischemia or to improve recovery after ischemia. The technique induces angiogenesis in ischemic muscle due to vascular endothelial growth factor (VEGF) receptor $2^{14}$, enhances ischemic tissue survival, blood flow, and angiogenesis ${ }^{15}$. It also increases the efficacy of cell therapy in chronic hind limb ischemia ${ }^{16}$, improves microcirculation blood flow of ischemic limbs in patients with peripheral arterial disease ${ }^{17}$, and improves perfusion and cardiac function in patients with ischemic heart failure ${ }^{18}$. Low-energy shock wave preconditioning is a simple IPC method that can reduce the renal oxidative stress and inflammation caused by high-energy shock wave lithotripsy ${ }^{19}$ and protect the kidneys from subsequent applications of high-energy shock wave therapy ${ }^{20-22}$.

However, it is unclear if low-energy shock wave preconditioning can reduce the renal IR injury caused by renal artery occlusion. Therefore, this study used an isolated kidney rat model to examine the effects of low-energy shock wave preconditioning on renal IR injury caused by renal artery occlusion.

\section{Methods}

The experimental protocol was approved by the Institutional Animal Care and Use Committees of Xi'an Jiaotong University. The experimental processes complied with the National Institutes of Health (NIH) Guide for the Care and Use of Laboratory Animals.

A total of 64 male Sprague Dawley rats $(200 \pm 10 \mathrm{~g})$ were provided by the Experimental Animal Center of the Medical School of Xi'an Jiaotong University.

The rats were anesthetized with an intraperitoneal injection of pentobarbital $(50 \mathrm{mg} / \mathrm{kg}$ ) and the depth of anesthesia was monitored by tail-pinch reflex test. After abdominal skin preparation, the rats were fixed to the operation table, disinfected, and a $2.5 \mathrm{~cm}$ midline abdominal incision made. The right kidney was removed, the left kidney was exposed, and silver clips were placed on the perirenal fat. The incision was sutured. A heat lamp was used to keep the animals warm for 0.5 hours after surgery. After surgery, the rats were allowed to recover for two weeks before the following experiments were performed.

The animals were randomly divided into four groups. Group $1(n=16)$ was the sham treatment group. Group $2(n=16)$ received low-energy shock wave preconditioning (LESP): following intraperitoneal injection of pentobarbital $(50 \mathrm{mg} / \mathrm{kg})$ for anesthesia, the hair on the left flank was removed and the rats were placed on the extracorporeal shock wave lithotripsy machine (HK.ESWL-Vm, Wikkon, 
Shenzhen, China). The machine has a focal zone (F2) diameter and length of about 1.2 and $5.7 \mathrm{~cm}$, respectively. The shock wave head was equipped with an electromagnetic shock wave emitter. The left flanks of the rats were tightly attached to the water bladder and a coupling agent was applied. X-ray imaging was used to identify the midpoint between the two silver clips; after accurate positioning, low-energy shock wave (12 kvm, 200 pulses) was applied, with a shock wave pulse frequency of $1 \mathrm{~Hz}$ and operation steps as shown in Figure 1. Group 3 $(n=16)$ was the LESP+IR group. In this group, low-energy shock wave preconditioning was performed as described in Group 2; the left renal artery was then occluded for 45 minutes: the rats were fixed on the operating table and an incision was made along the original surgical incision. Under the microscope, the left renal artery was isolated and occluded for 45 minutes, and then the incision was sutured. Group $4(n=16)$ received IR only, with the left renal artery occluded for 45 minutes, as described for Group 3.

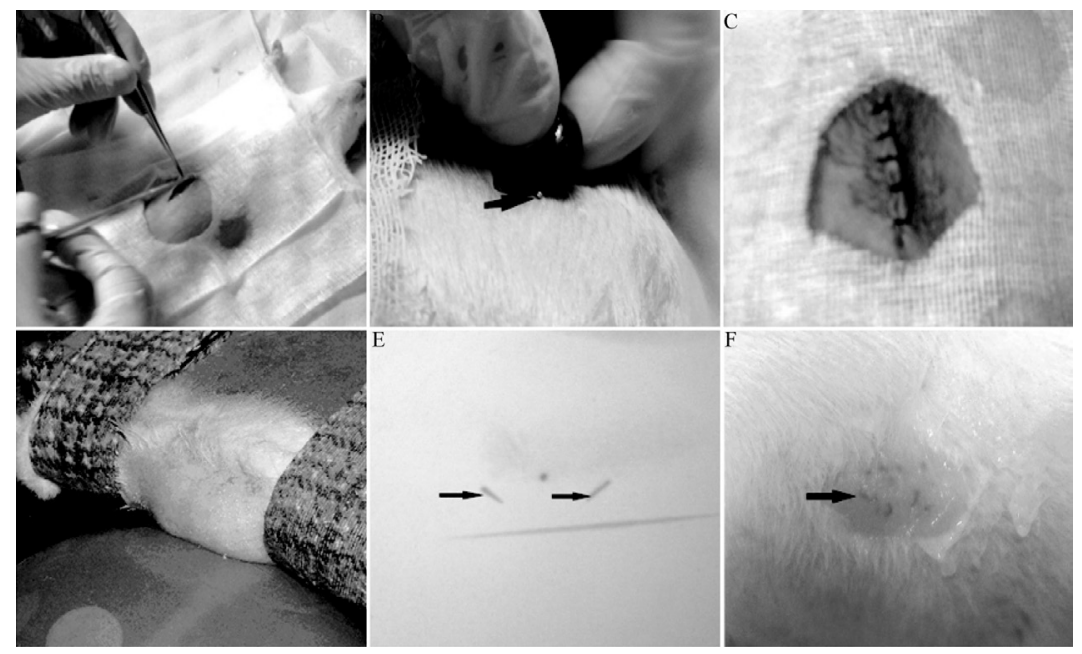

Figure 1 - The process of rat surgery and extracorporeal low energy shock wave precondition. A: Rat underwent anesthesia and surgery; B: The silver clips were fixed to the kidney; C: Suture the incision; D: Rat was fixed to extracorporeal lithotripsy; E: The focus was located at the midpoint of the two silver clips; F: Visible injury on rat skin after impact.

Eight rats from each group were sacrificed at 24 hours and one week after reperfusion. Blood was collected from the inferior vena cava and centrifuged at 3,000 rpm for $10 \mathrm{~min}$. The supernatants were collected and stored at $-80^{\circ} \mathrm{C}$ until testing. The left kidney of each rat was removed: kidney tissue homogenates were used for malondialdehyde (MDA) examination, and small pieces of kidney tissue samples were placed in $10 \%$ neutral buffered formalin solution.

Inducible nitric oxide synthase (iNOS) and MDA detection

Commercial iNOS and MDA detection kits were purchased from Nanjing Jiancheng Biological Engineering Company (Nanjing, China). Kidney tissue samples were weighed and ground, and lyase was added to a mass ratio of 1:9. The homogenizer was placed in an icebox for full homogenization at $4^{\circ} \mathrm{C}$ and $15.000 \mathrm{r} /$ minutes, and then centrifuged for about $20 \mathrm{~min}$. The supernatant was collected for MDA analysis. The MDA level in renal tissue was reported as MDA content per unit weight protein $(\mu \mathrm{mol} / \mathrm{mg})$. Serum neutrophil gelatinase-associated lipocalin (NGAL), kidney injury molecule-1 (KIM-1), creatinine ( $\mathrm{Cr}$ ), and cystatin C (Cys C), detection kits were purchased from Shanghai Westang Biotechnology Company (Shanghai, China). 
Hematoxylin and Eosin (HE) staining and microscopic examination

The renal sections were observed by HE stain and electric microscopy. An experienced renal pathologist who was blinded to the study group assignments performed morphologic assessment. A minimum of four fields for each kidney slide was examined. A grading scale of 0 to 4 was used to assess the degree of renal injury ${ }^{8}$.

\section{Statistical analysis}

Data were expressed as means \pm standard deviations. PASW Statistics for Windows, version 18.0 was used for statistical analysis. An independent sample $t$-test was performed for comparisons between groups.
$P<0.05$ was considered statistically significant.

\section{Results}

The groups 1 and 2 did not differ significantly in any indicator at the two time points

The results of oxygen free radical assessments in the groups 3 and 4 revealed serum iNOS activity levels $(\mathrm{U} / \mathrm{mL})$ in Group 3 and 4 were $15.19 \pm 3.19$ and $23.74 \pm 4.82$, respectively $(P=0.009)$, and MDA levels ( $\mu \mathrm{mol} /$ $\mathrm{mg}$ protein) in renal tissue were $14.19 \pm 4.13$ and $20.81 \pm 5.12$, respectively $(P<0.000)$. One week after reperfusion, serum iNOS activities in group 3 and group 4 were $6.50 \pm 2.47$ and $7.77 \pm 3.68$, respectively $(P=0.515)$, while MDA levels in renal tissue were $3.13 \pm 0.67$ and 3.24 \pm 0.63 , respectively $(P=0.540)$ (Table 1 ).

Table 1 - Serum iNOS $(\mathrm{U} / \mathrm{ml}$ ) and kidney tissue MDA ( $\mu \mathrm{mol} / \mathrm{mg}$ protein).

\begin{tabular}{lllll}
\hline Group $(\mathrm{n}=16)$ & iNos $(\mathrm{U} / \mathrm{ml})$ & & \multicolumn{2}{l}{ MDA ( $\mu \mathrm{mol} / \mathrm{mg}$ protein) } \\
& $\mathbf{2 4}$ hours & $\mathbf{1}$ week & $\mathbf{2 4}$ hours & $\mathbf{1}$ week \\
\hline Sham & $6.31 \pm 2.40$ & $7.29 \pm 2.65$ & $2.76 \pm 0.53$ & $2.91 \pm 0.94$ \\
LESP & $7.37 \pm 2.38$ & $8.82 \pm 2.49$ & $2.96 \pm 0.38$ & $3.01 \pm 0.51$ \\
LESP+IR & $15.19 \pm 3.19 * *$ & $6.50 \pm 2.47$ & $14.19 \pm 4.13^{* *}$ & $3.13 \pm 0.67$ \\
IR & $23.74 \pm 4.82^{*}$ & $7.77 \pm 3.68$ & $20.81 \pm 5.12^{*}$ & $3.24 \pm 0.63$
\end{tabular}

*Significantly different from Sham group and LESP group; ${ }^{* *}$ Significantly different from IR group; LESP: Low-Energy Shock Wave; IR: Ischemic Reperfusion.

Twenty four hours after reperfusion, the results of renal injury items in the group 3 and group 4 included serum NGAL $(\mathrm{pg} / \mathrm{mL})$ levels in the group 3 and group 4 were 4043.08 \pm 393.49 and $6,726.82 \pm 626.11$, respectively $(P<0.001)$ and serum $\mathrm{KIM}-1(\mathrm{pg} / \mathrm{mL})$ levels were $16,643.04 \pm 1,829.24$ and $23,160.54 \pm$
$3,481.38$, respectively $(P=0.001)$; one week after reperfusion, the serum NGAL $(\mathrm{pg} / \mathrm{mL})$ levels in the group 3 and group 4 were 2,002.53 \pm 223.20 vs. $2,801.05 \pm 474.88$, respectively $(P=0.011)$, while the serum KIM-1 $(\mathrm{pg} / \mathrm{mL})$ levels were 5,645.80 \pm 570.76 and 6,096.15 \pm $628.09(P=0.179)$, respectively (Table 2 ).

Table 2 - Serum NGAL (pg/ml)and KIM-1 (pg/ml) levels.

\begin{tabular}{|c|c|c|c|c|}
\hline \multirow{2}{*}{$\begin{array}{l}\text { Group } \\
(n=16)\end{array}$} & \multicolumn{2}{|l|}{ NGAL (pg/ml) } & \multicolumn{2}{|l|}{ KIM-1 (pg/ml) } \\
\hline & 24 hours & 1 week & 24 hours & 1 week \\
\hline Sham & $1638.16 \pm 144.10$ & $1688.45 \pm 154.72$ & $3772.71 \pm 703.97$ & $3725.41 \pm 517.17$ \\
\hline LESP & $1649.44 \pm 122.56$ & $1657.99 \pm 174.80$ & $4061.86 \pm 646.54$ & $3943.72 \pm 704.69$ \\
\hline LESP+IR & $4043.08 \pm 393.49 * *$ & $2002.53 \pm 223.20 * *$ & $16643.04 \pm 1829.24^{* *}$ & $5645.80 \pm 570.76^{*}$ \\
\hline IR & $6726.82 \pm 626.11^{*}$ & $2801.05 \pm 474.88 *$ & $23160.54 \pm 3481.38 *$ & $6096.15 \pm 628.09 *$ \\
\hline
\end{tabular}

*Significantly different from Sham group and LESP group; **Significantly different from IR group; LESP: Low-Energy Shock Wave; IR: Ischemic Reperfusion. 
Twenty four hours after reperfusion, the results of renal function assessment in group 3 and group 4 included serum $\mathrm{Cr}(\mu \mathrm{mol} / \mathrm{L})$ levels were $172.85 \pm 24.91$ and $212.26 \pm 27.60$ $(P=0.054)$ and serum Cys $C(\mathrm{ng} / \mathrm{mL})$ levels were $176.57 \pm 19.25$ and $220.25 \pm 35.81 \quad(P=0.030)$.
One week after reperfusion, the serum $\mathrm{Cr}$ $(\mu \mathrm{mol} / \mathrm{L})$ levels in group 3 and group 4 were $92.16 \pm 14.22$ and $102.04 \pm 13.03$, respectively $(P=0.184)$, while the serum Cys $C(\mathrm{ng} / \mathrm{mL})$ levels were $85.17 \pm 8.77$ and $111.97 \pm 17.60$, respectively $(P=0.007)$ (Table 3$)$.

Table 3 - Serum $\mathrm{Cr}(\mu \mathrm{mol} / \mathrm{L})$ and Cys C (ng/ml) levels.

\begin{tabular}{lllll}
\hline Group $(\mathrm{n}=16)$ & $\begin{array}{l}\text { Cr }(\mu \mathrm{mol} / \mathrm{L}) \\
\text { 24 hours }\end{array}$ & $\mathbf{1}$ week & $\begin{array}{l}\text { Cys C }(\mathrm{ng} / \mathrm{ml}) \\
\text { 24 hours }\end{array}$ & $\mathbf{1}$ week \\
\hline Sham & $56.87 \pm 7.55$ & $54.90 \pm 7.95$ & $50.27 \pm 8.74$ & $56.31 \pm 7.10$ \\
LESP & $60.28 \pm 10.10$ & $56.39 \pm 9.33$ & $50.15 \pm 12.03$ & $57.97 \pm 8.59$ \\
LESP+IR & $172.85 \pm 24.91^{*}$ & $92.16 \pm 14.22^{*}$ & $176.57 \pm 19.25^{* *}$ & $85.17 \pm 8.77^{* *}$ \\
IR & $212.26 \pm 27.60^{*}$ & $102.04 \pm 13.03^{*}$ & $220.25 \pm 35.81^{*}$ & $111.97 \pm 17.60^{*}$ \\
\hline
\end{tabular}

*Significantly different from Sham group and LESP group; **Significantly different from IR group; LESP: Low-Energy Shock Wave; IR: Ischemic Reperfusion.

Twenty four hours after reperfusion, light microscopy observation of the HE-stained renal sections revealed renal tubular epithelial cell swelling, renal tubular lumen narrowing or occlusion, renal tubular epithelial cell exfoliation, and visible capillaries congestion in group 3; group 4 showed more severe and larger range of renal tissue damage compared to the group 3. One week after reperfusion, the renal tissue morphology was essentially normal in both groups (Figure 2).

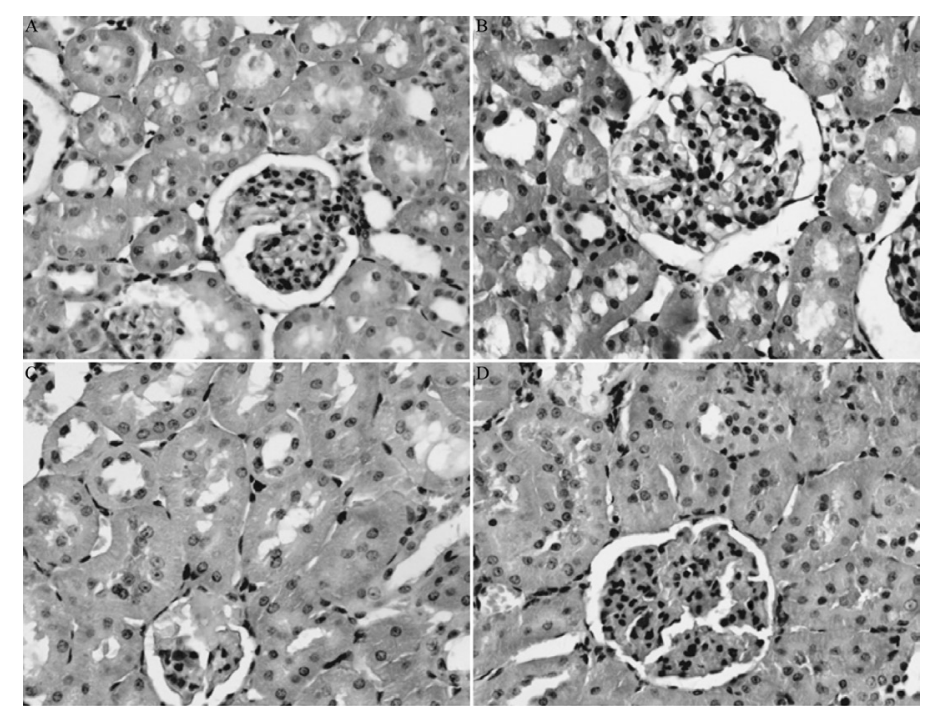

Figure 2 - Renal injury observed by light microscope. A, B: Sham and LESP, normal histology, glomerular and renal tubular epithelial cells, no swelling and degeneration, the cells were morphologically normal; C: LESP+IR, renal tubular epithelial cells swelling, renal tubular lumen narrowing or occlusion; $\mathbf{D}$ : IR, more severe and larger range of renal tissue damage that group LESP+IR, necrosis cell aggregation of cells to form tubetype (HE stain, x400). 
Observation of the renal sections by electric microscope 24 hours after reperfusion revealed renal tubule epithelial cell swelling and necrosis, local cytoplasm dissolution in renal tubular epithelial cells, disordered or disappeared microvillus, and mitochondrial edema or aggregation; nuclear pyknosis was observed in varying degrees; infolding of the plasma membrane occurred at different degrees of edema. The changes were more serious in samples from rats in the group 4. One week after reperfusion, the renal tissue injury was significantly reduced but had not yet returned to normal (Figure 3 ).

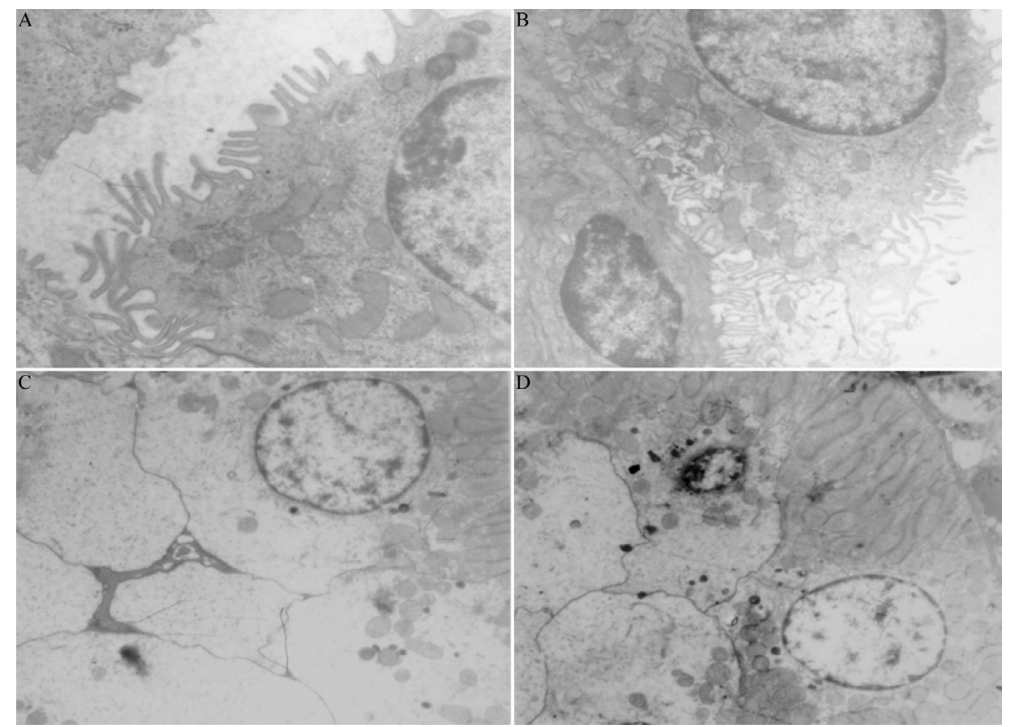

Figure 3 - Renal injury observed by electric microscope. A, B: Sham and LESP, normal histology, renal tubular epithelial cells, no swelling and degeneration, microvillus was clear and orderly, renal tubular lumen clearly (A: $500 \mathrm{~nm}$, Original magnification 15k; B: $500 \mathrm{~nm}$, Original magnification 10k); C: LESP+IR, renal tubule epithelial cells swell, renal tubular lumen narrow, filled with necrotic tissue $(1 \mathrm{~nm}$, Original magnification 6000); D: IR, renal tubule epithelial cell swell; degeneration and partial necrosis, exfoliated, renal tubular lumen disappeared (1nm, Original magnification 6000).

Twenty-four hours after reperfusion, the renal injury scores in group 1 , group 2 , group 3 and group 4 were $0.00 \pm 0.00,0.09 \pm$ $0.30,2.28 \pm 0.99$, and $3.22 \pm 0.75$, respectively; the renal tissue injury score in group 3 was significantly lower than that in group 4 $(P<0.001)$. One week after reperfusion, the renal injury scores in group 1 , group 2, group 3 and group 4 were $0.00 \pm 0.000 .00 \pm 0.00$, $0.59 \pm 0.61$, and $0.81 \pm 0.78$, respectively; the difference in scores between group 3 and group 4 were not statistically significant $(P=0.198)$ (Table 4).

Table 4 - Renal injury scores.

\begin{tabular}{llllll}
\hline Renal scores & $\begin{array}{l}\text { Group } \\
\text { Sham }\end{array}$ & LESP & LESP+IR & IR & P values \\
\hline 24 hours & $0.00 \pm 0.00$ & $0.09 \pm 0.30$ & $2.28 \pm 0.99 * *$ & $3.22 \pm 0.75^{*}$ & $P<0.001$ \\
1 week & $0.00 \pm 0.00$ & $0.00 \pm 0.00$ & $0.59 \pm 0.61^{*}$ & $0.81 \pm 0.78^{*}$ & $P=0.198$ \\
\hline
\end{tabular}

*Significantly different from Sham group and LESP group; **Significantly different from IR group; LESP: Low-Energy Shock Wave; IR: Ischemic Reperfusion. 


\section{- Discussion}

Renal artery occlusion may lead to renal ischemia-reperfusion injury during nephron sparing surgery ${ }^{4}$. For patients with anatomic or functional solitary kidney, and patients whose tumor is located in renal hilum or renal center, how to reduce renal ischemia-reperfusion injury caused by renal artery occlusion is particularly important $^{2}$. Evaluation of the protective effect of low-energy shock wave pretreatment from the viewpoint of renal injury indicators, 24 hours after reperfusion revealed significantly lower serum NGAL and KIM-1 levels in the LESP +IR group compared to those of the IR group. One week after reperfusion, the serum NGAL level in the LESP +IR group was significantly lower than that of the IR group, indicating that low-energy shock pretreatment may alleviate renal injury caused by renal artery occlusion.

Renal function is the essential purpose of renal injury protective treatments. Low energy shock wave pretreatment can reduce the damage of renal function caused by high energy shock wave damage ${ }^{20}$. Twenty-four hours after reperfusion, serum $\mathrm{Cr}$ and $\mathrm{Cys} \mathrm{C}$ levels in the LESP+IR group were significantly lower than those of the IR group. These findings indicate that renal artery occlusion for 45 minutes caused significant damage to renal function in the isolated renal rat model.

Free radical production is one of the most important mechanisms of tissue ischemia-reperfusion injury ${ }^{11}$, low-energy shock waves pretreatment can reduce the renal oxidative stress caused by high-energy shock wave lithotripsy ${ }^{19}$. From this study, 24 hours after reperfusion, serum iNOS and renal tissue MDA levels in the LESP+IR group were both significantly lower than those of the IR group, indicating that low-energy shock pretreatment can reduce free radicals induced by ischemia and reperfusion in a short time.

From the data of 24 hours, Serum,
iNOS, NGAL, KIM-1, Cys C levels, kidney tissue MDA, and renal scores all show that LESP has significant short-term protection effect. But, from the data of the 1 week, all indexes of LESP group were superior to IR group in numerical value, but only serum NGAL and Cys C showed statistical difference. From the experimental data, LESP seems to be only short-term protection. Whether LESP has long-term protective effects on ischemia-reperfusion injury, further research is needed.

\section{Conclusion}

Low-energy shock wave precondition can reduce the renal function damage caused by renal artery occlusion.

\section{References}

1. Shin SJ, Ko KJ, Kim TS, Ryoo HS, Sung HH, Jeon HG, Jeong BC, Seo SI, Lee HM, Choi HY, Jeon SS. Trends in the use of nephron-sparing surgery over 7 years: an analysis using the R.E.N.A.L. Nephrometry Scoring System. PLoS One. 2015 Nov 24;10(11):e0141709. doi: 10.1371/journal.pone.0141709.

2. Satasivam $P$, Rajarubendra N, Chia PH, Munshey A, Sengupta S, Bolton D. Trends in the use of of nephron-sparing surgery (NSS) at an Australian tertiary referral centre: an analysis of surgical decision-making using the R.E.N.A.L. nephrometry scoring system. BJU Int. 2012 May;109(9):1341-4. doi: 10.1111/j.1464-410X.2011.10595.x.

3. Meyer C, Hansen J, Becker A, Schmid M, Pradel L, Strini K, Chromecki T, JescheChromecki J, Fisch M, Zigeuner R, Chun FK. The adoption of nephron-sparing surgery in Europe - A trend analysis in two referral centers from Austria and Germany. Urol Int. 2016;96(3):330-6. doi: 10.1159/000442215.

4. Janetschek G. Perfusion/reperfusion injury following ischemia for nephron sparing surgery. Eur Urol Suppl. 2016;15(2):38. doi: 10.1016/S1569-9056(16)30012-4.

5. Lu J, Zu Q, Du Q, Xu Y, Zhang X, Dong J. Zero ischaemia laparoscopic nephron-sparing surgery by re-suturing. Contemp Oncol 
(Pozn). 2014;18(5):355-8. doi: 10.5114/ wo.2014.41385.

6. Patil MB, Gill IS. Zero-ischaemia robotic and laparoscopic partial nephrectomy (PN). BJU Int. 2011 Sep;108(5):780-92. doi: 10.1111/j.1464-410X.2011.10564.x.

7. Martin GL, Warner JN, Nateras RN, Andrews $P E$, Humphreys MR, Castle EP. Comparison of total, selective, and nonarterial clamping techniques during laparoscopic and robotassisted partial nephrectomy. J Endourol. 2012 Feb;26(2):152-6. doi: 10.1089/ end.2011.0304.

8. Torras J, Herrero-Fresneda I, Lloberas N, Riera M, Ma Cruzado J, Ma Grinyó J. Promising effects of ischemic preconditioning in renal transplantation. Kidney Int. 2002 Jun;61(6):2218-27. doi: 10.1046/j.15231755.2002.00360.x.

9. Li DY, Shi XJ, Li W, Sun XD, Wang GY. Ischemic preconditioning and remote ischemic preconditioning provide combined protective effect against ischemia/ reperfusion injury. Life Sci. 2016 Apr 1;150:76-80. doi: 10.1016/j.Ifs.2016.02.077.

10.Fröhlich GM, Meier P, White SK, Yellon DM, Hausenloy DJ. Myocardial reperfusion injury: looking beyond primary $\mathrm{PCl}$. Eur Heart J. 2013 Jun;34(23):1714-22. doi: 10.1093/eurheartj/eht090.

11.Wever KE, Menting TP, Rovers $M$, van der Vliet JA, Rongen GA, Masereeuw R, Ritskes-Hoitinga $M$, Hooijmans CR, Warlé $M$. Ischemic preconditioning in the animal kidney, a systematic review and metaanalysis. PLoS One. 2012;7(2):e32296. doi: 10.1371/journal.pone.0032296.

12.Xue TM, Tao LD, Zhang J, Zhang PJ, Liu $X$, Chen GF, Zhu YJ. Intestinal ischemic preconditioning reduces liver ischemia reperfusion injury in rats. Mol Med Rep. 2016 Mar;13(3):2511-7. doi: 10.3892/ mmr.2016.4817.

13.Ozbilgin $S$, Ozkardesler $S$, Akan $M$, Boztas N, Ozbilgin M, Ergur BU, Derici S, Guneli ME, Meseri R. Renal ischemia/ reperfusion injury in diabetic rats: the role of local ischemic preconditioning. Biomed Res Int. 2016;2016:8580475. doi: 10.1155/2016/8580475.

14. Holfeld J, Tepeköylü C, Blunder S, Lobenwein $D$, Kirchmair E, Dietl $M$, Kozaryn R, Lener $D$, Theurl M, Paulus $P$, Kirchmair R, Grimm M.
Low energy shock wave therapy induces angiogenesis in acute hind-limb ischemia via VEGF receptor 2 phosphorylation. PLoS One. 2014 Aug 5;9(8):e103982. doi: 10.1371/journal.pone.0103982.

15. Keil H, Mueller W, Herold-Mende C, Gebhard MM, Germann G, Engel $H$, Reichenberger MA. Preoperative shock wave treatment enhances ischemic tissue survival, blood flow and angiogenesis in a rat skin flap model. Int J Surg. 2011;9(4):292-6. doi: 10.1016/j.ijsu.2011.01.003.

16.Aicher A, Heeschen C, Sasaki K, Urbich C, Zeiher AM, Dimmeler S. Low-energy shock wave for enhancing recruitment of endothelial progenitor cells: a new modality to increase efficacy of cell therapy in chronic hind limb ischemia. Circulation. 2006 Dec 19;114(25):2823-30. doi: 10.1161/ CIRCULATIONAHA.106.628623.

17. Tara S, Miyamoto M, Takagi G, KirinokiIchikawa S, Tezuka A, Hada T, Takagi I. Lowenergy extracorporeal shock wave therapy improves microcirculation blood flow of ischemic limbs in patients with peripheral arterial disease: pilot study. J Nippon Med Sch. 2014;81(1):19-27. doi: 10.1272/ jnms.81.19.

18.Peng $\mathrm{Y}$, Li R, Guo T. Extracorporeal cardiac shock wave therapy improved perfusion and cardiac function of patients with ischemic heart failure. Circulation. 2013;128(22):A14516.

19. Clark DL, Connors BA, Handa RK, Evan AP. Pretreatment with low-energy shock waves reduces the renal oxidative stress and inflammation caused by high-energy shock wave lithotripsy. Urol Res. 2011 Dec;39(6):437-42. doi: 10.1007/s00240011-0372-z.

20.Willis LR, Evan AP, Connors BA, Handa RK, Blomgren PM, Lingeman JE. Prevention of lithotripsy-inducedrenalinjurybypretreating kidneys with low-energy shock waves. J Am Soc Nephrol. 2006 Mar;17(3):663-73. doi: 10.1681/ASN.2005060634.

21.Fernández $F$, Domínguez $A$, Castaño $E$, Loske AM. Out-of-focus low pressure pulse pretreatment to the whole kidney to reduce renal injury during shock wave lithotripsy: an in vivo study using a rabbit model. J Endourol. 2013 Jun;27(6):774-82. doi: 10.1089/end.2012.0673. 
22. Handa RK, Bailey MR, Paun M, Gao S, Connors BA, Willis LR, Evan AP. Pretreatment with low-energy shock waves induces renal vasoconstriction during standard shock wave lithotripsy (SWL): a treatment protocol known to reduce lithotripsy-induced renal injury. BJU Int. 2009 May;103(9):1270-4. doi: 10.1111/j.1464-410X.2008.08277.x.

\section{Correspondence:}

Tie Chong

Department of Urology

The Second Affiliated Hospital, Xi'an Jiaotong

University

No.157 West 5 Road

Xi'an 710004, Shaanxi Province China

Phone: +86 2987679442

Fax: +86 2987679323

yqxdoc@126.com

Received: Mar 02, 2017

Review: May 08, 2017

Accepted: June 05, 2017

Conflict of interest: none
Financial source: National Natural Science Foundation of China (81000293)
${ }^{1}$ Research performed at Urology Surgery Institute, Department of Urology, the Second Affiliated Hospital, Xi'an Jiaotong University, Shaanxi Province, China. 